\title{
Saudi Patients Compliance With the Antibiotic Course in Dentistry
}

\author{
Ali Assiry ${ }^{1^{*}}$, Sundar Ramalingam ${ }^{2}$, Abdulrahman A Al Amri ${ }^{3}$, Ali A Al-Mujaly ${ }^{4}$ and Yousef S Al-Elyani ${ }^{5}$ \\ ${ }^{1}$ Department of Pediatric Dentistry College of Dentistry, Najran university, Saudi Arabia \\ ${ }^{2}$ Department of maxillofacial surgery, King Saud University College of Dentistry, Saudi Arabia \\ ${ }^{3}$ Al-Iman General Hospital, Ministry of Health, Saudi Arabia \\ ${ }^{4}$ Military Hospital, Saudi Arabia \\ ${ }^{5}$ Military hospital, Saudi Arabia
}

"Corresponding autor: Ali Assiry, Paediatric Dentistry, Department of Preventive Dental Science, College of Dentistry, Najran University, Ministry of Education Najran, Saudi Arabia, Tel: +00966507700624; E-mail: ali100mm@hotmail.com

Recieved Date: April 24, 2017; Accepted Date: April 26, 2017; Published Date: April 29, 2017

Copyright: (C) 2017 Assiry A, et al. This is an open-access article distributed under the terms of the Creative Commons Attribution License, which permits unrestricted use, distribution, and reproduction in any medium, provided the original author and source are credited.

\begin{abstract}
Objective: The aim of our study is to assess compliance of Saudi patients with the course of prescribed antibiotics in dentistry by knowing whether patients use antibiotic every day.

Method: A cross sectional study has been conducted using a questionnaire as an instrument for data collection from patients. Survey responses were tabulated and analyzed statistically to find the number of compliant patients to the prescribed course of antibiotics, as well as to find if there is any association between compliance and age, gender, and education level.
\end{abstract}

Result: 300 questionnaires were distributed among a cross section of the population in 4 dental centers in Riyadh. Only 126 patients responded, giving a response rate of $42 \%$. According to this study, the percentage of fully compliant patients was $60.3 \%$. There was no significant association between variables and compliance. The reasons for non-compliance among patients included: symptoms disappeared $(62 \%)$, fear of side effects of medication $(18 \%)$, no clear instructions about the importance of completing the full course $(16 \%)$, and patient carelessness $(4 \%)$.

Conclusion: Around $60 \%$ of patients complied with the full course of antibiotics as prescribed.

Keywords: Antibiotics; Compliance; Compliance survey; Oral antibiotics

\section{Introduction}

Compliance (also called adherence or capacitance) as described by WHO is "the degree to which a patient correctly follows medical advice. Most commonly, it refers to medication or drug compliance, but it can also apply to other situations such as medical device use, selfcare, self-directed exercise, or therapy sessions". Both patients and health workers affect compliance. Making a positive relationship between the health care provider and patient is considered the most important factor to improving compliance [1].

Non-compliance in a medical parlance that can be defined as any deviation by the patient from a physician's instructions. Noncompliance to the prescribed medication can lead to the failure of the treatment. It should be noted that treatment failure can also result from several factors, but non-compliance can be considered the most critical factor. Another important factor isdeciding on the best choice of antibiotic that treats the most likely causative bacterial infection with determining the appropriate duration, frequency and dose [2].

In a study reported in the literature, it has been shown that there are many variables to discriminate between compliance and noncompliance toward medications. According to the study, discriminating variables related to the patient include: health status, employment status, knowing the name of the tablet, level of anxiety, perceived difficulty in compliance, observed anger, and distance between patient and the health care provider during the time of prescription and assertiveness in the consultation. On the other hand, discriminating variables related to doctors/caregivers included: provision of advice on the duration of treatment, complexity of dosage schedule, age and experience [3].

In fact, bacterial infection is common in dentistry, as a result of which, antibiotics prescribed for treatment are frequent as well. One study has reported that odontogenic infection results in $10 \%$ of all antibiotics that are prescribed daily [4]. Therefore, the misuse of antibiotic therapy includes both failure to complete the course and skipping doses, which can potentially expose the patient to suboptimal antibiotic therapy. Such behavior in taking antibiotics can lead to insufficient exposure for eradicating infectious bacteria and potentially create an environment that promotes antibiotic resistance. Therefore, misuse of antibiotic therapy has ramifications on healthcare costs, treatment failure, wasted hospitalization time and the use of more medications [5-7]. The aim of the present study is to assess compliance with the full course of antibiotics as prescribed by a health care provider to treat dental problems among Saudi patients in order to find out up to which level people are aware in using antibiotics properly. 


\section{Materials and Methods}

A cross sectional studywith convenience sampling was conducted using a questionnaire with close-ended questions. Patients included in the survey were originally fromSaudi Arabia, aged above 16 years, free from any debilitating medical illnesses or were well-controlled by medications (ASA I/ASA II), having a past history of dental treatment or consultation for which antibiotics were prescribed, and prescription done by a health care provider, physician, dentist or pharmacist. Patients requiring prophylactic antibiotic coverage because of a high risk of developing endocarditis, pediatric patients, or self-prescribed patients were all excluded from our study [8]. Each patient filled out the questionnaire which included: age, gender, the level of the education, pre-existing health conditions, reason for using antibiotics, the number of days of antibiotic course, the compliance with the full course of antibiotics every day as prescribed, the number of days that the antibiotics were not taken in the case of non-compliance, and selecting the reason that led to non-compliance [9]. Questionnaires were collected, tabulated and subjected to statistical analysis using SPSS (Version 19). Descriptive analysis and Chi-squared test (pvalue $<0.05)$ were performed to assess any significant association between variables and compliance.

\section{Results}

The questionnaires were distributed to 300 patients in 4 dental centers in Riyadh: Security Forces Hospital, King Saud Medical City, Prince Sultan Medical City and Dental College of King Saud University. Only 126 patients responded, 101 men and 25 women. The response rate was $42 \%$. The percentage of compliers to the antibiotic therapy course among the respondents was $60.3 \%$ compared to $39.7 \%$ of non-compliers.

\begin{tabular}{|l|l|l|l|}
\hline \multirow{2}{*}{ Age } & \multicolumn{2}{l|}{ Antibiotic compliance } & \multirow{2}{*}{ Total } \\
\cline { 2 - 3 } & Yes & No & \multirow{2}{*}{} \\
\hline $11-20$ & 7 & 0 & 7 \\
\hline $21-30$ & 31 & 19 & 50 \\
\hline $31-40$ & 11 & 15 & 26 \\
\hline $41-50$ & 20 & 7 & 27 \\
\hline $51-60$ & 6 & 7 & 13 \\
\hline $61-70$ & 1 & 2 & 3 \\
\hline Total & 76 & 50 & 126 \\
\hline
\end{tabular}

Table 1: Association between age of the patient and antibiotic compliance.

\begin{tabular}{|l|l|l|l|}
\hline \multirow{2}{*}{ Gender } & \multicolumn{2}{|l|}{ Antibiotic compliance } & \multirow{2}{*}{ Total } \\
\cline { 2 - 3 } & Yes & No & \\
\hline Male & 60 & 41 & 101 \\
\hline Female & 16 & 9 & 25 \\
\hline Total & 76 & 50 & 126 \\
\hline
\end{tabular}

Table 2: Association between gender of the patient and antibiotic compliance.
Ages ranged from 17 to 67 , with the mean age of 42 . In our study, we divided the sample into 6 groups according to age (11-20, 21-30, $31-40,41-50,51-60$ and 61-70). The largest number of patients was aged 21-30 (50 patients), and the smallest number was 61-70 (3 patients only), (Table 1). The number of women in our study was limited. However, compliance seems slightly better among women (64\%) compared to men (59.4\%), (Table 2).

\begin{tabular}{|l|l|l|l|}
\hline \multirow{2}{*}{ Educational level } & \multicolumn{2}{|l|}{ Antibiotic compliance } & Total \\
\cline { 2 - 4 } & Yes & No & \\
\hline Primary & 3 & 1 & 4 \\
\hline Intermediate & 9 & 7 & 16 \\
\hline High school & 24 & 18 & 42 \\
\hline Higher education & 40 & 24 & 64 \\
\hline Total & 76 & 50 & 126 \\
\hline
\end{tabular}

Table 3: Association between educational level of the patient and antibiotic compliance.

\begin{tabular}{|l|l|l|}
\hline Reasons & Frequency & Percent \\
\hline Dental abscess & 48 & $38.1 \%$ \\
\hline Tooth extraction & 31 & $24.6 \%$ \\
\hline Toothache & 20 & $15.9 \%$ \\
\hline RCT & 10 & $7.9 \%$ \\
\hline Minor oral surgery & 9 & $7.1 \%$ \\
\hline Dental implant & 8 & $6.4 \%$ \\
\hline
\end{tabular}

Table 4: Reasons of using antibiotic therapy.

Based on the educational level, we divided patients into 4 groups according to their last educational degree: primary school, intermediate school, high school and higher education. The largest group included in our study was the last group (64 subjects), followed by the high school group (42 subjects), intermediate school group (16 subjects) and primary school group (4 subjects), (Table 3 ).

\begin{tabular}{|l|l|l|}
\hline Reasons & Frequency & Percentage \\
\hline $\begin{array}{l}\text { Disappearance of } \\
\text { symptoms }\end{array}$ & 31 & $62 \%$ \\
\hline $\begin{array}{l}\text { Fear of antibiotic side } \\
\text { effects }\end{array}$ & 9 & $18 \%$ \\
\hline $\begin{array}{l}\text { No instructions from } \\
\text { HCP }\end{array}$ & 8 & $16 \%$ \\
\hline Patient carelessness & 2 & $4 \%$ \\
\hline
\end{tabular}

Table 5: Reasons of non-compliance.

The reasons for the prescription of antibiotic therapy were: dental abscess $38.1 \%$ (48), tooth extraction $24.6 \%$ (31), toothache $15.9 \%$ (20), root canal treatment $7.9 \%(10)$, minor oral surgery $7.1 \%$ (9), and dental implant 6.4\% (8) (Table 4). The reasons for non-compliance that we 
suggested for patients were: the disappearance of symptoms $62 \%$ (31/50), fear of antibiotic side effects $18 \%$ (9/50), no instruction from health care provider about the importance to complete the full course of antibiotic treatment $16 \%(8 / 50)$, patient carelessness $4 \%(2 / 50)$ and other reasons $(0 / 50)$, (Table 5).The duration of the antibiotic course did not seem to affect patient compliance.

\section{Discussion}

Non-compliance in Saudi Arabia has been noticed not only in medications. In fact, many articles found non-compliance towards primary health care appointments, antenatal visits, and antiepileptic therapy $[10,11]$. Several studies have shown that one of the major problems in health care is non-compliance with the prescribed medications. Much money and resources have beenwasted as a result of non-compliance, which has led to inadequate treatment, recurrent infectionor life threatening resistance to medications [12]

It is very important to be active against the pathogens in order to achieve complete cure from bacterial infections. Potent activity is achieved by administering the best choice of antibiotics withrecommended dosage, frequency, and duration. However, strict adherence of the patient to the antibiotic treatment is essential for the treatment success. Therefore, misuse of antibiotics can develop resistance of pathogenic bacteria and consequently complicatethe management of bacterial infections among the population [13].

In the daily practice, oral antibiotics are used for treating most microbial infections. Therefore, we chose in this study to assess the behavior of Saudi patients towards using antibiotics that exclusively treat dental infections.

Overall, the percentage of non-compliers was 39.7\%, which indicates misuse of antibiotics. Based on the results in Table 5, compliance with antibiotic therapy was affected by health care providers. Thus, the population must be sufficiently educated regarding the ineffectiveness of antibiotic therapy when instructions are not followed.

\section{Conclusion}

The result of our study shows around $60 \%$ of patients were complying with the full course of antibiotics as prescribed. Therefore, health workers should make more effort to enhance the proper use of antibiotics in our population.

\section{Acknowledgments}

We thank all the chairmen of dental departments of all selected hospitals (Security Forces Hospital, King Saud Medical City, Prince Sultan Medical City and Dental College of King Saud University) for allowing us to distribute our survey.

\section{References}

1. De Geest S, Sabaté E (2003) Adherence to long-term therapies: evidence for action. European Journal of Cardiovascular Nursing 2: 323-323.

2. Kardaz P (2002) Patient compliance with antibiotic treatment for respiratory tract infections. Journal of Antimicrobial Chemotherapy 49: 897-903.

3. Cockburn J, Gibberd RW, Reid AL, Sanson-Fisher RW (1987) Determinants of non-compliance with short term antibiotic regimens. Br Med J 295: 814-818.

4. Poveda Roda R, Bagán JV, Sanchis Bielsa JM, Carbonell Pastor E (2007) Antibiotic use in dental practice: A review. Medicina Oral Patología Oral y Cirugía Bucal 12: 186-192.

5. Dajani AS (1996) Adherence to physicians' instructions as a factor in managing streptococcal pharyngitis. Pediatrics 97: 976-980.

6. Sclar DA, Tartaglione TA, Fine MJ (1994) Overview of issues related to medical compliance with implications for the outpatient management of infectious diseases. Infectious Agents and Disease 3: 266-273.

7. Al-Shammari SA, Khoja T, Al-Yamani MJMS (1995) Compliance with short-term antibiotic therapy among patients attending primary health centres in Riyadh, Saudi Arabia. Journal of the Royal Society of Health 115: 231-234.

8. Adebayo ET, Dairo M (2005) Patients compliance with instructions after oral surgery in Nigeria. Journal of community medicine and primary health care 17: 38-44.

9. Al-Shammari S (1991) Failure to keep primary care appointments in Saudi Arabia. Br J Gen Pract 41: 301-302.

10. Al-Shammari SA, Khoja T, Jarallah JS (1994) The pattern of antenatal visits with emphasis on gestational age at booking in Riyadh Health Centres. Journal of the Royal Society of Health 114: 62-66.

11. Bawazir SA (1993) Prescribing patterns of ambulatory care physicians in Saudi Arabia. Annals of Saudi medicine 13: 172-177.

12. Yamamoto Y, Kadota J, Watanabe A, Yamanaka N, Tateda K, et al. (2012) Compliance with oral antibiotic regimens and associated factors in Japan: Compliance survey of multiple oral antibiotics. Scandinavian journal of infectious diseases 44: 93-99.

13. Al-Shammari SA, Khoja T, Al-Yamani MJMS (1995) Compliance with short-term antibiotic therapy among patients attending primary health centres in Riyadh, Saudi Arabia. Journal of the Royal Society of Health 115: 231-234. 